Nick Glozier

MB BS, FRANZCP PhD

Professor of Psychological Medicine

Geoffrey H Tofler

MB BS, MD, FRACP

Professor of Preventiv Cardiology $^{2}$

David M Colquhoun

MB BS, FRACP, FCSANZ,

Associate Professor of Medicine $^{3}$

Stephen J Bunker RN, PhD

Adjunct Senior Lecturer

David M Clarke

PhD, FRACGP, FRANZCP,

Professor and Psychiatrist,

Consultation-Liaison

Psychiatry Service, Monas Medical Centre

David L Hare DPM, FRACP, FCSANZ Professorial Fellow and Coordinator of

Cardiovascular Research ${ }^{6}$

Ian B Hickie

MD, FRANZCP, FASSA

Professor of Psychiatry

James Tatoulis

MB BS, MD, FRACS Chief Medical Advisor

David R Thompson MA, PhD, FRCN

Professor of Nursing ${ }^{8}$

Alison Wilson MBA

National Manage Clinical Programs

Maree G Branagan MPH,

Project Officer Clinical Programs

1 Brain and Mind Research Institute, University of Sydney,

Sydney, NSW.

2 Cardiology Department Royal North Shore Hospital,

University of Sydney,

Sydney, NSW.

3 University of Queensland

Brisbane, QLD.

4 Greater Green Triangle University Department of

Rural Health, Flinders

University and Deakin

University, Warrnambool,

VIC

5 School of Psychology and

Psychiatry, Monas

University, Melbourne, VIC

6 University of Melbourne

Melbourne, VIC

7 National Heart

Foundation of Australia,

Melbourne, VIC

8 Cardiovascular Research Centre, Australian Catholic

University, Melbourne, VIC

Maree.branagan@ heartfoundation.org.au

doi: 10.5694/mjal3.10440

Guidelines

\title{
Psychosocial risk factors for coronary heart disease
}

\author{
A consensus statement from the National Heart Foundation of Australia
}

n 2003, the National Heart Foundation of Australia (NHFA) published a position statement relating to psychosocial risk factors and coronary heart disease (CHD). ${ }^{1}$ Here, we provide an updated review of the literature on psychosocial stressors, to complement a separate consensus statement from the Expert Working Group on depression and $\mathrm{CHD}^{2}$ Psychosocial stressors include chronic stressors (in particular, work stress), acute individual stressors (such as bereavement or job loss) and acute population stressors (such as earthquakes and sporting events). The process for developing this consensus statement is described in Box 1. Treatment decisions should take into account the individual clinical circumstances of each patient.

\section{Chronic stressors and coronary heart disease}

\section{Chronic work stress}

The previous NHFA review found that there was neither strong nor consistent evidence of a causal association between work-related stressors and $\mathrm{CHD} .{ }^{1}$ However, there is plausible evidence for work stress having a biological impact. ${ }^{4}$ Furthermore, work stress has a prominent place in the public perception of potential causes of CHD, particularly heart attacks. ${ }^{5}$

Most of the literature evaluating the effects of work stress on cardiovascular disease (CVD) has focused on job strain $^{6}$ and effort-reward imbalance. ${ }^{7}$ Recently, the literature has broadened to include other concepts, such as job insecurity, ${ }^{8}$ organisational justice, ${ }^{9}$ job satisfaction ${ }^{10}$ and work hours. ${ }^{11}$ Throughout the literature, these concepts generally refer to individuals' perceptions rather than external ratings of work stress. Studies of the impact of work stress on the development of CHD have been comprehensively reviewed since 2003 . $^{12-16}$ Differing study methodology (in particular, the method used to assess work stress) has a strong effect on whether or not an association between work stress and CHD is found. ${ }^{12,15}$

\section{Job strain}

People who report that the demands of their work are too great and that they have too little control over how and when their work is performed are considered to be experiencing "job strain". ${ }^{6}$ One review found that for high versus low job strain, the age- and sex-adjusted relative risk (RR) of CHD was 1.43 (95\% CI, 1.15-1.84), but this was not significant after adjustment for standard CHD risk factors and potential mediators. ${ }^{13}$ Another review found that a

\section{Summary \\ - In 2003, the National Heart Foundation of Australia published a position statement on psychosocial risk factors and coronary heart disease (CHD). This consensus statement provides an updated review of the literature on psychosocial stressors, including chronic stressors (in particular, work stress), acute individual stressors and acute population stressors, to guide health professionals based on current evidence. It complements a separate updated statement on depression and CHD. \\ - Perceived chronic job strain and shift work are associated with a small absolute increased risk of developing CHD, but there is limited evidence regarding their effect on the prognosis of $\mathrm{CHD}$.}

- Evidence regarding a relationship between CHD and job (in)security, job satisfaction, working hours, effortreward imbalance and job loss is inconclusive.

- Expert consensus is that workplace programs aimed at weight loss, exercise and other standard cardiovascular risk factors may have positive outcomes for these risk factors, but no evidence is available regarding the effect of such programs on the development of $\mathrm{CHD}$.

- Social isolation after myocardial infarction (MI) is associated with an adverse prognosis. Expert consensus is that although measures to reduce social isolation are likely to produce positive psychosocial effects, it is unclear whether this would also improve CHD outcomes.

- Acute emotional stress may trigger Ml or takotsubo ("stress") cardiomyopathy, but the absolute increase in transient risk from an individual stressor is low.

- Psychosocial stressors have an impact on CHD, but clinical significance and prevention require further study.

- Awareness of the potential for increased cardiovascular risk among populations exposed to natural disasters and other conditions of extreme stress may be useful for emergency services response planning.

- Wider public access to defibrillators should be available where large populations gather, such as sporting venues and airports, and as part of the response to natural and other disasters.

majority of studies of men found no independent association between job strain and CHD, while studies of women suggested trends toward an association. ${ }^{12}$ The relevance of this difference between the sexes is unclear. A European meta-analysis of individual participant data showed that for the $15 \%$ of employed participants who reported high levels of job strain, the hazard ratio (HR) for an incident CHD event was 1.23 (95\% CI, 1.10-1.37), compared with 
1 Process used to develop this National Heart Foundation of Australia consensus statement

The Expert Working Group members performed relevant literature searches for systematic and literature reviews using key search phrases including, but not limited to, "cardiovascular diseases", "myocardial infarction", "angina pectoris" and "coronary disease" combined with "job strain", "demand", "control", "effort reward imbalance", "job (dis)satisfaction", "job (in)security", "organisational justice", "work conditions", "long working hours", "social isolation", "triggers", "emotion", "stress", "anger", "anxiety", "life events" or "bereavement". Searches were limited to evidence published in English between 2003 and December 2012 and were complemented by reference lists compiled from reviews and personal collections of the Expert Working Group members.

The evidence statements (Box 2 ) and the recommendation (Box 3 ) made in this consensus statement have been graded according to National Health and Medical Research Council guidelines. ${ }^{3}$ The aetiology or prognosis hierarchies were used, except where there was an appropriate or ethical intervention available that dictated use of the intervention hierarchy (Appendix). Where there was an absence of interventional evidence, no clinical recommendations were made. This consensus statement is a summary of the current state of knowledge. The Royal Australian and New Zealand College of Psychiatrists and the Cardiac Society of Australia and New Zealand were consulted during the development of this document and have endorsed its content.

the participants reporting low levels of job strain. ${ }^{16}$ However, job strain only accounted for $3.4 \%$ of the overall population attributable fraction (PAF; a reflection of the contribution of a risk factor to a disease) of CHD. This PAF is much less than that for standard CHD risks, such as smoking or hypertension. Confirming this, the Whitehall II study demonstrated that adding information on job strain does not improve 10-year risk prediction for CHD above the standard Framingham risk score. ${ }^{17}$

\section{Effort-reward imbalance}

This is the perception of an imbalance between the effort of work (which includes the demands and challenges of the work itself and the effort of balancing work with other aspects of one's life) and the rewards of work (financial rewards, increased self-esteem and advancement opportunities). ${ }^{7}$ The RR for the combination of high effort and low reward in predicting $\mathrm{CHD}$ in one review was not statistically significant $(1.58 ; 95 \% \mathrm{CI}, 0.84-2.97){ }^{13}$ a finding of a trend only, that was confirmed by another review. ${ }^{12}$

\section{Organisational injustice}

The perception of organisational injustice (unfair treatment at work) has been associated with a significant RR of CHD (1.47; 95\% CI, 1.12-1.95). ${ }^{13}$ However, as almost all of the evidence for this came from the Whitehall II study, no generalised conclusion about the association between organisational injustice and CHD can be reached.

\section{Shift work}

The impact of shift work on CHD was thoroughly reviewed and analysed in 2012. ${ }^{14}$ Shift work was found to be associated with a moderate increase in myocardial infarction (MI) (RR, 1.23; 95\% CI, 1.15-1.31) and CHD events (RR, 1.24; 95\% CI, 1.10-1.39), but not with increased rates of mortality. All shift work schedules studied, with the exception of evening shifts, were associated with a higher risk of $\mathrm{CHD}$ events, even after adjusting for unhealthy behaviour and other CHD risks.

\section{Other types of work stress}

The evidence of an association between the development of CHD and job (in)security, ${ }^{8}$ job satisfaction ${ }^{10}$ and working hours ${ }^{11}$ is mixed, and no firm conclusions can be made at this stage. It is recognised that the potential for bias in this area is large.

\section{Work stress and prognosis of $\mathrm{CHD}$}

We identified no systematic reviews on this topic. Two Canadian studies have analysed work stress as a prognostic factor after a first CHD event. ${ }^{18,19}$ An association was found between chronic job strain and recurrent CHD in the period 2.2 years or more after a first coronary event (HR, 2.20; 95\% CI, 1.32-3.66). ${ }^{18}$ Job strain remained an independent predictor of recurrent CHD after adjustment for potential confounders. In the other study, a high effort-reward imbalance showed a trend toward an association with recurrent CHD (HR, 1.75; 95\% CI, 0.99-3.08), particularly in women. ${ }^{19}$ This association appeared to be explained by low reward rather than by high levels of effort.

\section{Social isolation and social support}

There has been consistent prospective evidence that poor social relationships are associated with higher mortality rates from all causes. ${ }^{20,21}$ The most comprehensive review suggested a $50 \%$ increased likelihood of survival for participants with stronger social relationships, with no differences between the sexes. ${ }^{20}$

However, a systematic review found that there is limited evidence for low social support or social isolation being a marker of, or risk factor for, the development of CHD in healthy people. ${ }^{22} \mathrm{~A}$ more recent study evaluating people either at risk of or with existing atherothrombosis showed that people who lived alone were at higher risk of cardiovascular death than those who lived with someone $(8.6 \% \mathrm{v}$ $6.8 \% ; P<0.01){ }^{23}$

In contrast, "prognostic" studies of the effect of low social support after MI are more numerous and compelling. ${ }^{22,24-26}$ These studies have consistently found low social support to be a marker of poor prognosis, being associated with increased mortality, readmission and reinfarction rates. In a review of prognostic studies, ${ }^{22}$ low "functional support" (the aid that is provided to an individual by his or her social network, including help doing tasks and emotional support) increased cardiac and allcause mortality. Adjusting for other risk factors had little or no effect on these results (HR for all-cause mortality, 1.59; $95 \%$ CI, 1.21-2.08). The effect of "structural support" (number and frequency rather than "quality" of contacts) was less evident (adjusted HR for combined cardiac or allcause mortality, 1.12; 95\% CI, 0.98-1.29).

Reducing social isolation and increasing social support are difficult to achieve. In the Enhancing Recovery in Coronary Heart Disease Patients (ENRICHD) trial, which involved people with low social support or depression after an MI, those who received counselling sessions showed greater improvement on the five-item ENRICHD Social Support Instrument than did the controls. ${ }^{27}$ However, this was not associated with any improvement in CHD outcomes. There have been no treatment studies on which recommendations about targeting social support as a way of improving CHD outcomes can be based.

\section{Acute stressors and coronary heart disease}

The 2003 NHFA position statement found that acute lifeevent stressors could trigger CHD events but that it was 
difficult to study and quantify the magnitude of their effects. ${ }^{1}$ Since then, further publications have supported the link between acute stressors and CHD. However, there is potential for recall bias in this evidence, arising from case-crossover $^{28}$ and observational ${ }^{29}$ studies, and for other potential confounders or varying individual responses to stressors to influence the results. While many psychological stressors have a clear time of initiation, others are less precise.

Several reviews have examined the relationship between acute psychological stressors and $\mathrm{CHD}^{30-33}$ One review assessed studies of triggers of non-fatal $\mathrm{MI}$ and calculated PAFs. ${ }^{34}$ Taking into account the odds ratio (OR) and the prevalence of exposures, the estimated PAFs included negative emotions (3.9\%) and anger (3.1\%).

\section{Pathophysiology}

There are several mechanisms by which acute psychological stress might trigger an acute MI. ${ }^{35}$ Psychological stress produces significant increases in heart rate and blood pressure that may lead to increased myocardial oxygen demand and plaque disruption. There is also evidence that mental stress may lead to a primary reduction in myocardial oxygen supply. Whereas coronary arteries of people without CHD dilate during mental stress, impaired dilation and even constriction have been demonstrated in atherosclerotic arteries. ${ }^{36}$ In some studies, mental stress has been found to enhance platelet aggregation. ${ }^{37}$

\section{Individual stressors}

\section{Acute emotional responses}

Individual studies have shown a varying transient RR of about 2-9 (compared with baseline) for anger triggering MI, typically using a 2-hour hazard period after an episode of anger. Anger shortly before MI has been reported in $2 \%-17 \%$ of different populations. ${ }^{38-40}$ Acute anger episodes have also been reported to trigger ventricular arrhythmias. ${ }^{41}$ A higher likelihood of anger triggering MI has been observed in people with socioeconomic deprivation and lower educational attainment. ${ }^{42}$

Acute anxiety episodes are also associated with a transient increase in cardiac risk. In the Determinants of Myocardial Infarction Onset Study (the Onset study), experiencing anxiety symptoms in the 2 hours before MI symptom onset was associated with a significant RR of 1.6 (95\% CI, 1.1-2.2; $P=0.01) .{ }^{38}$ However, these studies are prone to recall bias.

\section{Bereavement}

Increased cardiac mortality in bereaved people is well described. ${ }^{33,43}$ In a cohort of middle-aged widowers, a $40 \%$ relative increase in mortality rate was observed in the first 6 months after bereavement. ${ }^{43}$ Using the new criteria in the fifth edition of the Diagnostic and statistical manual of mental disorders, many of these bereaved individuals could now be diagnosed as having "depression" ${ }^{44}$ The risk appears to be maximal in the first few weeks. In the Onset study, there was a 21.1 -fold (95\% CI, 13.1-34.1) increase in incidence rate ratio of non-fatal $\mathrm{MI}$ in the 24 hours after bereavement, with a fourfold increase in the first month after bereavement. $^{45}$

\section{Acute work-related stressors and job loss}

Acute work stressors (eg, high-pressure deadline), when linked to negative emotions, have been associated with a transient increase in risk of $\mathrm{MI}(\mathrm{OR}, 6.0 ; 95 \% \mathrm{CI}, 1.8$ 20.3). ${ }^{46}$ However, confirmatory studies are needed.

Job loss is a major stressor that may disrupt socioeconomic dimensions, such as income and social connections, and is commonly thought to be a cause of adverse health events. ${ }^{47-49}$ The United States Health and Retirement Survey found that involuntary job loss (eg, from workplace closures or redundancies) among older workers was associated with a more than doubling in MI (HR, 2.48; 95\% CI, 1.49-4.14) relative to working people, after adjustment for potential confounders. ${ }^{47}$ A greater number of job losses experienced by an individual was associated with a greater risk of MI. ${ }^{49}$ This risk increased incrementally from one job loss (HR, 1.22; 95\% CI, 1.04-1.42) to four or more cumulative job losses (HR, 1.63; 95\% CI, 1.29-2.07). The risk of MI was elevated within the first year of unemployment (HR, 1.27; 95\% CI, 1.01-1.60) but not thereafter.

In contrast, studies from Europe and New Zealand have shown no link between job loss and CVD. ${ }^{50-53}$ The reasons for these different findings may relate to differing study approaches. The US studies all used self-reporting for determination of $\mathrm{CHD}^{47-49}$ whereas the European and New Zealand studies used national data linkages for more robust determination of CHD deaths and hospitalisation. ${ }^{50-53}$ Also, the context may have an influence; for example, in the US, employment is important in accessing health care. The impact of job loss during a recession, when such loss is more common, is different to the impact of job loss during a boom. ${ }^{54}$ Paradoxically, country-level data have shown temporal associations of decreasing unemployment with increased deaths from CVD. ${ }^{55,56}$ It has been suggested that this effect may reflect people using the extra time to undertake healthier behaviour. Overall, while job loss may have detrimental economic and psychological consequences, its association with CHD remains unclear.

\section{Population stressors}

\section{Natural and other disasters}

Earthquakes and wartime missile attacks are associated with acute increases in cardiovascular event rates, ${ }^{29,57-59}$ possibly moderated by the time of the event. It is postulated that the added stress of abrupt awakening may have contributed to the triggering of MI by the 1994 Los Angeles earthquake, which occurred at $4.31 \mathrm{am} .{ }^{59}$ In the 60 days after the September 11 terrorist attacks in 2001, there was a $49 \%$ increase in patients with MI admitted through New York emergency departments, compared with the 60 days before $(118 \mathrm{v} 79 ; P=0.01) .{ }^{60}$

\section{Sporting events}

Sporting events provide another example of population stress. $^{61,62}$ On the day of the 1996 European football championship quarterfinal in which the Netherlands narrowly lost to France, Dutch men had an increased RR of mortality from MI or stroke of 1.51 (95\% CI, 1.08-2.09). However, there was no increased risk for Dutch women. ${ }^{61}$ A German study of the football World Cup provided further evidence for the triggering of cardiovascular events 
during emotional stress associated with watching sporting events. $^{62}$

\section{Takotsubo cardiomyopathy}

There has been increased recognition of takotsubo cardiomyopathy and its relationship to acute emotional stress. ${ }^{63-65}$ The use of angiography has led to the recognition of takotsubo cardiomyopathy in $1 \%-3 \%$ of patients presenting with suspected acute coronary syndrome. A distinctive abnormality of left ventricular contraction, leading to a systolic appearance on angiography that resembles the short, narrow neck and round bottom of a Japanese octopus trap (a takotsubo), gave the entity its name. Takotsubo cardiomyopathy is characterised by signs and symptoms of myocardial ischaemia in the absence of obstructive CHD. ${ }^{63}$ Acute myocarditis may present with similar symptoms and with normal coronary arteries, but without the distinctive left ventricular appearance of takotsubo cardiomyopathy. Although incidence rates vary, an episode of acute psychological stress frequently seems to trigger the onset of takotsubo cardiomyopathy, which is also referred to as "stress cardiomyopathy". However, the absolute incidence is low. ${ }^{63}$ Women, particularly postmenopausal women, are a susceptible population, accounting for up to $90 \%$ of affected individuals. ${ }^{63}$ Takotsubo cardiomyopathy appears to have a neurohormonal basis associated with high catecholamine levels. ${ }^{65}$ Full recovery of left ventricular function usually occurs within several days. ${ }^{65}$

\section{Preventive strategies for triggered acute risk}

While the evidence supports a link between acute psychological triggers and cardiovascular risk, there is no convincing evidence for specific prevention at an individual level. It is therefore important to note that the absolute risk from a single triggering event, and likewise the risk reduction from any single episode of therapy, is very low. ${ }^{38,66}$ Any low additional transient risk also needs to be considered in the context of an individual's overall risk factor profile. Suggested approaches to protecting against MI triggered by acute emotional stress include reinforcing the value of general cardiovascular risk factor modification, with an emphasis on lowering lipid levels, reducing blood pressure, smoking cessation, regular physical activity and maintaining a healthy weight. ${ }^{66} \mathrm{~A}$ range of resources regarding these measures and general workplace wellness are available from health promotion organisations including the NHFA. ${ }^{67}$ Other approaches include education about reducing anxiety and anger responses to stress. ${ }^{68}$ The use of agents that have a cardioprotective effect, such as aspirin and $\beta$-blockers, has been shown to alter the physiological response to acute stressors and may result in reduced risk of trigger-related $\mathrm{MI}^{38,66}$ although this requires further study.

From a population perspective, the recognition that acute stressors can trigger CHD supports the need for cardiac care to be available for large gatherings of people who may experience mental stress. This could include availability of public-access defibrillators at sporting venues and airports, or as part of the initial rescue response to natural and other disasters, such as earthquakes. ${ }^{29,69,70}$
2 National Heart Foundation of Australia evidence statements regarding psychosocial stressors and coronary heart disease (CHD)

\section{Evidence statement}

Grade

Level

\section{Chronic stressors}

\section{Risk factors for onset of CHD (aetiology)}

1 High job strain increases the risk of $\mathrm{CHD}$

2 Shift work increases the risk of CHD

3 Limited evidence that social isolation is a risk factor for $\mathrm{CHD}$

C* $\left.\quad\right|^{\dagger}$

C* $\left.\right|^{\dagger}$

Outcome of CHD (prognosis)

1 Limited evidence that high job strain increases the risk of a poor $\mathrm{CHD}$ prognosis

2 Social isolation increases the risk of a poor $\mathrm{CHD}$ prognosis

D* $\quad \mathrm{I}^{\dagger}$

\section{Acute stressors}

$1 \mathrm{Ml}$ can be precipitated by negative emotional states

2 CHD events can be precipitated by bereavement

3 No consistent evidence that involuntary job loss causes $\mathrm{CHD}$

4 Takotsubo cardiomyopathy can be precipitated by acute emotional stress

5 Acute population stressors (eg, earthquakes, missile attacks and sporting events) may transiently increase cardiovascular events

$\mathrm{Ml}=$ myocardial infarction. * Clinical impact is unclear. $†$ Using National Health and Medical Research Council (NHMRC) aetiology hierarchy. ${ }^{3} \ddagger$ Using NHMRC prognosis hierarchy. ${ }^{3}$

3 National Heart Foundation of Australia recommendation regarding psychosocial stressors and coronary heart disease

\section{Recommendation}

1 Wider public access to defibrillators should be available where

large populations gather, such as sporting venues and airports, and

as part of the response to natural and other disasters

* Using National Health and Medical Research Council intervention hierarchy. ${ }^{3}$

Grade Level

B III-2*

\section{* Using National Health and Medical Research Council intervention hierarchy.}

\section{Conclusion}

A summary of the key evidence-based points is provided in Box 2 and Box 3.

There is now consistent observational evidence that some aspects of work stress, high perceived job strain and shift work are associated with a small increased risk for development of CHD. These studies have been conducted almost entirely in northern Europe and may not be generalisable to the Australian context, with its different health system, job market and sociodemographic structure. There is also considerable publication bias in the available literature, and the measures of work stress are often only assessed once and are highly variable.

The increased RR of CHD events (about 20\%-30\%) may account for between 3\% (job strain) and 7\% (shift work) of all CHD events, as job strain and shift work are so common. Although notable, this effect is far weaker than that from standard CHD risk factors such as smoking, hypertension, abnormal lipid levels and depression. Knowledge of an individual's work stress levels does not appear to help clinicians in predicting future CHD events. Furthermore, no studies have been conducted to show whether any intervention for work stress can reduce the development of CHD. With the many factors involved and the uncommon occurrence of CHD events in working populations, the likelihood of workplace stress prevention programs demonstrating an effect on CHD events is 
remote. More promising is the potential of workplace programs aimed specifically at weight loss, exercise and other standard cardiovascular risk factors, although no evidence is yet available regarding the effect of such programs on the development of CHD. ${ }^{71}$ Insufficient evidence was found for an association between CHD and organisational injustice, job (in)security or satisfaction, or working hours, and no firm conclusions can be made about these at this stage.

Given the large body of consistent observational evidence that social isolation after an $\mathrm{MI}$ is associated with an adverse prognosis, attempts to enhance social support and reduce isolation should be encouraged. Such attempts will almost certainly produce positive psychosocial effects for most people, even though there is no definitive evidence that they will result in improved CHD outcomes.

Extensive literature supports a role for acute emotional stress in triggering MI and takotsubo cardiomyopathy, with potential mechanisms for the link described. However, the absolute increase in transient risk from an individual stressor is generally very low.

While there is evidence of a link between acute psychological triggers and $\mathrm{CHD}$, there is no convincing evidence for specific prevention at an individual level. However, there is a rationale to consider minimising cardiac risk factors to offer some protection against MI. Efforts to interrupt the link between the stressor and the cardiovascular event by non-pharmacological and pharmacological means require further research. The recognition that acute stressors can trigger CHD events supports the NHFA recommendation that wider public access to defibrillators be made available where large groups of people gather, such as sporting venues and airports, and as part of the response to natural and other disasters. From a public health perspective, awareness of the potential for increased cardiovascular risk among populations exposed to natural disasters and other conditions of extreme stress may be useful for emergency services response planning.

Acknowledgements: We thank Brian Oldenburg and Adrienne O'Neil for their consultation and contribution to the content of this document.

Competing interests: Nick Glozier has been funded under a strategic research grant program by beyondblue and the NHFA. Geoffrey Tofler has conducted investigatorinitiated research into bereavement, depression and cardiovascular risk, and triggering of cardiovascular disease and acute prevention, including effect of low-dose aspirin and $\beta$-blockers. He has received lecture fees from industry including from Servier and Boehringer Ingelheim. David Colquhoun has been a member of advisory groups for industry including for MSD, Pfizer (Lipid advisory group) and Abbott (Fish oil advisory group). He has undertaken research for Boehringer Ingelheim (RELY trial), Abbott (SCOUT trial), BMS (SAVOR trial), and Sanofi-Aventis (PALLAS and ORIGIN Trials). He is also a member of the Gallipoli Research Foundation Scientific Committee. David Hare has received research, fellowship and consultancy funds from the NHMRC, NHFA, Austin Medical Research Foundation, beyondblue and Diabetes Australia. He has received payment for research projects, consultancies, travel, advisory board memberships and lectures from industry including Abbott, Amgen, AstraZeneca, Biotronic, BMS, Boehringer Ingelheim, CSL-Biotherapies, Hoffmann-LaRoche, Hospira, Lundbeck (Denmark), Medtronic, Menarini, Merck KA (Germany), Merck (US), MSD, Pfizer, Roche, SanofiAventis, Servier and Wyeth. Ian Hickie was supported by an NHMRC Australia Fellowship (464914). He is a member of the new Australian National Mental Health Commission. He has led a range of community-based and pharmaceutical industry-supported depression training programs (including Servier, Pfizer, AstraZeneca, Janssen and Eli Lilly). His current investigator-initiated studies are supported by Servier and Pfizer. There are no relevant disclosures

for the other authors.

Provenance: Not commissioned; externally peer reviewed.

1 Bunker SJ, Colquhoun DM, Esler MD, et al. "Stress" and coronary heart disease: psychosocial risk factors. Med J Aust 2003; 178: 272-276.

2 Colquhoun DM, Bunker SJ, Clarke DM, et al. Screening, referral and treatment for depression in patients with coronary heart disease. Med J Aust 2013; 198: 483-484.
3 National Health and Medical Research Council. NHMRC additional levels of evidence and grades for recommendations for developers of guidelines. December 2009. https://www.nhmrc.gov.au/_files_nhmrc/file/guidelines/ developers/nhmrc_levels_grades_evidence_120423.pdf (accessed Aug 2012).

4 Chandola T, Heraclides A, Kumari M. Psychophysiological biomarkers of workplace stressors. Neurosci Biobehav Rev 2010; 35: 51-57.

5 French D, Maissi E, Marteau TM. The purpose of attributing cause: beliefs about the causes of myocardial infarction. Soc Sci Med 2005; 60: 1411-1421.

6 Karasek RA, Theorell T. Healthy work: stress, productivity and the reconstruction of working life. New York: Basic Books, 1990.

7 Siegrist J. Adverse health effects of high-effort/low-reward conditions. J Occup Health Psychol 1996; 1: 27-41.

8 Slopen N, Glynn RJ, Buring JE, et al. Job strain, job insecurity, and incident cardiovascular disease in the Women's Health Study: results from a 10-year prospective study. PLOS One 2012; 7: e40512.

9 Kivimäki M, Ferrie JE, Brunner E, et al. Justice at work and reduced risk of coronary heart disease among employees: the Whitehall II Study. Arch Intern Med 2005; 165: 2245-2251.

10 Huisman M, Van Lenthe F, Avendano M, Mackenbach J. The contribution of job characteristics to socioeconomic inequalities in incidence of myocardial infarction. Soc Sci Med 2008; 66: 2240-2252.

11 Kivimäki M, Batty GD, Hamer M, et al. Using additional information on working hours to predict coronary heart disease: a cohort study. Ann Intern Med 2011; 154: 457-463.

12 Eller NH, Netterstrøm B, Gyntelberg F, et al. Work-related psychosocial factors and the development of ischemic heart disease: a systematic review. Cardiol Rev 2009; 17: 83-97.

13 Kivimäki M, Virtanen M, Elovainio M, et al. Work stress in the etiology of coronary heart disease -- a meta-analysis. Scand J Work Environ Health 2006; 32: 431-442.

14 Vyas MV, Garg AX, lansavichus AV, et al. Shift work and vascular events: systematic review and meta-analysis. BMJ 2012; 345: e4800.

15 Szerencsi K, van Amelsvoort LG, Viechtbauer W, et al. The association between study characteristics and outcome in the relation between job stress and cardiovascular disease - a multilevel meta-regression analysis. Scand J Work Environ Health 2012; 38: 489-502.

16 Kivimäki M, Nyberg ST, Batty GD, et al; IPD-Work Consortium. Job strain as a risk factor for coronary heart disease: a collaborative meta-analysis of individual participant data. Lancet 2012; 380: 1491-1497.

17 Kivimäki M, Nyberg ST, Batty GD, et al. Does adding information on job strain improve risk prediction for coronary heart disease beyond the standard Framingham risk score? The Whitehall II study. Int J Epidemiol 2011; 40: 1577-1584.

18 Aboa-Eboulé C, Brisson C, Maunsell E, et al. Job strain and risk of acute recurrent coronary heart disease events. JAMA 2007; 298: 1652-1660.

19 Aboa-Eboulé C, Brisson C, Maunsell E, et al. Effort-reward imbalance at work and recurrent coronary heart disease events: a 4-year prospective study of post-myocardial infarction patients. Psychosom Med 2011; 73: 436-447.

20 Holt-Lunstad J, Smith TB, Layton JB. Social relationships and mortality risk: a meta-analytic review. PLOS Med 2010; 7: el000316.

21 Uchino BN, Bowen K, Carlisle M, Birmingham W. Psychological pathways linking social support to health outcomes: a visit with the "ghosts" of research past, present, and future. Soc Sci Med 2012; 74: 949-957.

22 Barth J, Schneider S, von Känel R. Lack of social support in the etiology and the prognosis of coronary heart disease: a systematic review and meta-analysis. Psychosom Med 2010; 72: 229-238.

23 Udell JA, Steg PG, Scirica BM, et al; REduction of Atherothrombosis for Continued Health (REACH) Registry Investigators. Living alone and cardiovascular risk in outpatients at risk of or with atherothrombosis. Arch Intern Med 2012; 172: 1086-1095.

24 Ruberman W, WeinblattE, Goldberg JD, Chaudhary BS. Psychosocial influences on mortality after myocardial infarction. NEngl J Med 1984; 311: 552-559.

25 Frasure-Smith N, Lespérance F, Gravel G, et al. Social support, depression, and mortality during the first year after myocardial infarction. Circulation 2000; 101: 1919-1924.

26 Bucholz EM, Rathore SS, Gosch K, et al. Effect of living alone on patient outcomes after hospitalization for acute myocardial infarction. Am J Cardiol 2011; 108: 943-948.

27 Berkman LF, Blumenthal J, Burg M, et al. Effects of treating depression and low perceived social support on clinical events after myocardial infarction: the Enhancing Recovery in Coronary Heart Disease Patients (ENRICHD) randomized trial. JAMA 2003; 289: 3106-3116.

28 Maclure $M$. The case-crossover design: a method for studying transient effects on the risk of acute events. Am J Epidemiol 1991; 133: 144-153.

29 Leor J, Kloner RA. The Northridge earthquake as a trigger for acute myocardial infarction. Am J Cardiol 1996; 77: 1230-1232.

30 Steptoe A, Brydon L. Emotional triggering of cardiac events. Neurosci Biobehav Rev 2009; 33: 63-70.

31 Kloner RA. Natural and unnatural triggers of myocardial infarction. Prog Cardiovasc Dis 2006; 48: 285-300. 
32 Strike PC, Steptoe A. Behavioral and emotional triggers of acute coronary syndromes: a systematic review and critique. Psychosom Med 2005; 67: 179-186.

33 Buckley T, McKinley S, Tofler G, Bartrop R. Cardiovascular risk in early bereavement: a literature review and proposed mechanisms. Int J Nurs Stud 2010; 47: 229-238.

34 Nawrot TS, Perez L, Künzli N, et al. Public health importance of triggers of myocardial infarction: a comparative risk assessment. Lancet 2011; 377: 732-740.

35 Strike PC, Magid K, Whitehead DL, et al. Pathophysiological processes underlying emotional triggering of acute cardiac events. Proc Natl Acad Sci US A 2006; 103 4322-4327.

36 Yeung AC, Vekshtein VI, Krantz DS, et al. The effect of atherosclerosis on the vasomotor response of coronary arteries to mental stress. N Engl J Med 1991; 325: 1551-1556.

37 Levine SP, Towell BL, Suarez AM, et al. Platelet activation and secretion associated with emotional stress. Circulation 1985; 71: 1129-1134.

38 Mittleman MA, Maclure M, Sherwood JB, et al. Triggering of acute myocardial infarction onset by episodes of anger. Determinants of Myocardial Infarction Onset Study Investigators. Circulation 1995; 92: 1720-1725.

39 Möller J, Hallqvist J, Diderichsen F, et al. Do episodes of anger trigger myocardial infarction? A case-crossover analysis in the Stockholm Heart Epidemiology Program (SHEEP). Psychosom Med 1999; 61: 842-849.

40 Strike PC, Perkins-Porras L, Whitehead DL, et al. Triggering of acute coronary syndromes by physical exertion and anger: clinical and sociodemographic characteristics. Heart 2006; 92: 1035-1040.

41 Lampert R, Joska T, Burg MM, et al. Emotional and physical precipitants of ventricular arrhythmia. Circulation 2002; 106: 1800-1805.

42 Mittleman MA, Maclure M, Nachnani M, et al. Educational attainment, anger, and the risk of triggering myocardial infarction onset. The Determinants of Myocardial Infarction Onset Study Investigators. Arch Intern Med 1997; 157: 769-775

43 Young M, Benjamin B, Wallis C. The mortality of widowers. Lancet 1963; 2: 454-456.

44 American Psychiatric Association. Diagnostic and statistical manual of mental disorders (DSM-5). 5th ed. Washington, DC: APA, 2013.

45 Mostofsky E, Maclure M, Sherwood JB, et al. Risk of acute myocardial infarction after the death of a significant person in one's life: the Determinants of Myocardial Infarction Onset Study. Circulation 2012;125: 491-496.

46 Möller J, Theorell T, de Faire U, et al. Work related stressful life events and the risk of myocardial infarction. Case-control and case-crossover analyses within the Stockholm heart epidemiology programme (SHEEP). J Epidemiol Community Health 2005; 59: 23-30.

47 Gallo WT, Teng HM, Falba TA, et al. The impact of late career job loss on myocardial infarction and stroke: a 10 year follow up using the health and retirement survey. Occup Environ Med 2006; 63: 683-687.

48 Gallo WT, Bradley EH, Falba TA, et al. Involuntary job loss as a risk factor for subsequent myocardial infarction and stroke: findings from the Health and Retirement Survey. Am J Ind Med 2004; 45: 408-416.

49 Dupre ME, George LK, Liu G, Peterson ED. The cumulative effect of unemployment on risks for acute myocardial infarction. Arch Intern Med 2012; 172: 1731-1737.

50 Eliason M, Storrie D. Job loss is bad for your health - Swedish evidence on cause-specific hospitalization following involuntary job loss. Soc Sci Med 2009; 68: 1396-1406.

51 Martikainen P, Mäki N, Jäntti M. The effects of workplace downsizing on cause-specific mortality: a register-based follow-up study of Finnish men and women remaining in employment. J Epidemiol Community Health 2008; 62: 1008-1013.

52 Browning M, Dano AM, Heinesen E. Job displacement and stress-related health outcomes. Health Econ 2006; 15: 1061-1075.

53 Keefe V, Reid P, Ormsby C, et al: Ngäti Kahungunu Iwi Incorporated. Serious health events following involuntary job loss in New Zealand meat processing workers. Int J Epidemiol 2002; 31: 1155-1161.

54 Martikainen P, Mäki N, Jäntti M. The effects of unemployment on mortality following workplace downsizing and workplace closure: a register-based follow-up study of Finnish men and women during economic boom and recession. Am J Epidemiol 2007; 165: 1070-1075.

55 Gerdtham UG, Ruhm CJ. Deaths rise in good economic times: evidence from the OECD. Econ Hum Biol 2006; 4: 298-316.

56 Lin SJ. Economic fluctuations and health outcome: a panel analysis of AsiaPacific countries. Appl Econ 2009; 41: 519-530. doi: 10.1080/ 00036840701720754.

57 Leor J, Poole WK, Kloner RA. Sudden cardiac death triggered by an earthquake. NEngl J Med 1996; 334: 413-419.

58 Meisel SR, Kutz I, Dayan KI, et al. Effect of Iraqi missile war on incidence of acute myocardial infarction and sudden death in Israeli civilians. Lancet 1991; 338: 660-661.

59 Brown DL. Disparate effects of the 1989 Loma Prieta and 1994 Northridge earthquakes on hospital admissions for acute myocardial infarction: importance of superimposition of triggers. Am Heart J 1999; 137: 830-836.
60 Allegra JR, Mostashari F, Rothman J, et al. Cardiac events in New Jersey after the September 11, 2001, terrorist attack. J Urban Health 2005; 82: 358-363.

61 Witte DR, Bots ML, Hoes AW, Grobbee DE. Cardiovascular mortality in Dutch men during 1996 European football championship: longitudinal population study. BMJ 2000; 321: 1552-1554.

62 Wilbert-Lampen U, Leistner D, Greven S, et al. Cardiovascular events during World Cup soccer. NEngl J Med 2008; 358: 475-483.

63 Lindsay J, Paixao A, Chao T, Pichard AD. Pathogenesis of the takotsubo syndrome: a unifying hypothesis. Am J Cardiol 2010; 106: 1360-1363.

64 Prasad A, Lerman A, Rihal CS. Apical ballooning syndrome (Tako-Tsubo or stress cardiomyopathy): a mimic of acute myocardial infarction. Am Heart J 2008; 155: 408-417.

65 Wittstein IS, Thiemann DR, Lima JA, et al. Neurohumoral features of myocardial stunning due to sudden emotional stress. N Engl J Med 2005; 352 : 539-548.

66 Tofler GH, Muller JE. Triggering of acute cardiovascular disease and potentia preventive strategies. Circulation 2006; 114: 1863-1872.

67 Heart Foundation, Cancer Council NSW, PANORG Sydney University. Healthy workplace guide: ten steps to implementing a workplace health program. Sydney: National Heart Foundation of Australia, 2011. http://www.heart foundation.org.au/active-living/Documents/Healthy\%20workplace $\% 20$ guide.pdf (accessed Jun 2013).

68 Mittleman MA, Mostofsky E. Physical, psychological and chemical triggers of acute cardiovascular events: preventive strategies. Circulation 2011; 124 346-354.

69 Weisfeldt ML, Sitlani CM, Ornato JP, et al. Survival after application of automatic external defibrillators before arrival of the emergency medical system: evaluation in the resuscitation outcomes consortium population of 21 million. J Am Coll Cardiol 2010; 55: 1713-1720.

70 Winkle RA. The effectiveness and cost effectiveness of public-access defibrillation. Clin Cardiol 2010; 33: 396-399.

71 van Dongen JM, Proper KI, van Wier MF, et al. A systematic review of the costeffectiveness of worksite physical activity and/or nutrition programs. Scand J Work Environ Health 2012; 38: 393-408.

Appendix: Definition of National Health and Medical Research Council (NHMRC) grades of recommendations and evidence hierarchy*

\section{Definition of NHMRC grades of recommendations}

\section{Grade Description}

A Body of evidence can be trusted to guide practice

B Body of evidence can be trusted to guide practice in most situations

C Body of evidence provides some support for recommendation(s) but care should be taken in its application

D Body of evidence is weak and recommendation must be applied with caution

NHMRC evidence hierarchy: designation of levels of evidence

Level Interventio

Aetiology

| $\quad$ A systematic review of level II studies

A systematic review of level II studies

A systematic review of level II studies

II $\quad$ a randomised controlled trial

A prospective cohort study

A prospective cohort Apros
study

III-1 A pseudorandomised controlled trial (ie, alternate allocation or some other

All or none All or none

III-2 method)

Non-randomised, experimental trial

Cohort study

- Case-control study

Interrupted time series with a control group

III-3 A comparative study without concurrent controls:

- Historical control study

- Two or more single arm study

- Interrupted time series without a parallel control group

IV Case series with either post-test or pre-test/post-test outcomes

Analysis of
prognostic
factors among
persons in a
single arm of a
randomised
controlled trial
A retrospective
cohort study

- A retrospective cohort study cohort study

- Acasecontrol study

ase series, or cohort study of persons at different stages of disease

* From NHMRC additional levels of evidence and grades for recommendations for developers of guidelines ${ }^{3}$ 